Check for updates

The BMJ

Cite this as: BMJ 2021;374:n1977

http://dx.doi.org/10.1136/bmj.n1977

Published: 10 August 2021

\section{Doctors have faced "worrying levels of abuse" in past month, BMA reports}

\section{Elisabeth Mahase}

Just over half (51\%) of GPs and 30\% of hospital doctors have reported experiencing verbal abuse in the past month, a survey of 2478 doctors and medical students in England, Wales, and Northern Ireland has found.

The survey, carried out by the BMA, found that doctors have faced "worrying levels of abuse" at a time while also dealing with the greatest health crisis in a generation, the covid-19 pandemic. A fifth of the GPs reported being threatened.

Half of all respondents (51\%) had witnessed violence or abuse against other staff, and this was especially high $(67 \%)$ for those working in general practice.

Hospital doctors were the most likely to report abuse of nurses $(87 \%)$ or other doctors $(65 \%)$, while in general practice $96 \%$ of those who had seen colleagues face abuse said this was directed at reception staff.

Two thirds (67\%) of the GPs responding to the survey said that their experience of abuse, threatening behaviour, or violence had worsened in the past year, and, although the doctors listed a variety of factors, most (75\% of GPs and $54 \%$ of hospital doctors) said the perpetrator was dissatisfied with the service or access.

Richard Vautrey, chair of the BMA's General Practitioners Committee, said, "Facing such abuse leaves doctors fearing for the safety of themselves, their colleagues, and their loved ones, which can have a profound effect on their wellbeing. It can leave even the most resilient GP feeling alienated and undervalued, leaving them questioning their career when the NHS can ill afford to lose any more staff in general practice. Meanwhile, being on the receiving end of rudeness can impact productivity and the quality of work, ultimately threatening patient care."

Vautrey has called on the government and NHS England to have an "honest public conversation" about the "precarious state the NHS now finds itself in after 18 months of managing a pandemic, so that people have realistic expectations, and to prevent staff bearing the brunt of frustration and anger."

Reports of abuse of health and social care staff have been rife during the pandemic. A survey by the Medical Protection Society found that 52\% of staff had received threats of physical abuse while working on the covid-19 vaccination programme and that $53 \%$ reported that their surgery or vaccination centre had been defaced by antivaccination material. ${ }^{1}$

Also, GPs have reported facing angry patients when asking them to get tested for covid-19, a situation not helped by lack of public messaging about the symptoms of the delta variant or about the fact that vaccination doesn't mean you can't be infected by SARS-CoV-2. ${ }^{2}$

At last year's conference of local medical committees in England, GPs said that NHS England and NHS Improvement's habit of briefing journalists before communicating with the profession had led to a rise in complaints and abuse received by GPs. They were referring to an episode where journalists had been briefed on a letter to GPs reminding them that patients must be offered face to face appointments. GPs called on NHS England and NHS Improvement to apologise for these "abhorrent and insulting" communications. ${ }^{3}$

The chair of the BMA's Consultants Committee, Vishal Sharma, said, "We cannot let people take out their frustration at a system on individual doctors or their colleagues, who truly are doing their best in the most difficult of situations. Even before the pandemic we were vastly understaffed, and abusive behaviour will drive more and more talented and experienced doctors away from the NHS at a time when we need them most ... We urge our patients to afford the same compassion to staff that they are shown in hospital, after what has been the most horrific year of our careers.”

\section{One GP's account of abuse}

Describing the recent abuse she has received, a GP partner in southwest England said, "In just the last week I have been shouted at because I asked someone to do a PCR test for their new cough and fever, and I was called the most horrifically offensive name after I asked someone not to come into the surgery waiting room with a cough and instead asked them to come to our onsite 'hot clinic' where people with covid symptoms can be seen safely.

“I was also told to 'go back to where you come from' by a patient who was unhappy at me being unable to tell headlines about practices being closed haven't helped at all. A few months ago a patient I was seeing face to face, less than three hours after she rang the surgery, told me it was 'impossible to see a doctor as you're not seeing patients' ... This feels so unfair and unkind when we have never closed and never stopped seeing patients.

"These behaviours are causing staff members, from receptionists to nurses and GPs, to want to quit. Our local practice managers are so distressed by the unrelenting complaints and poor behaviour that they are leaving in droves. The social contract that general practice prides itself on ... seems to have broken down, and people think it's ok to be rude and unkind."

Rimmer A. Covid-19: GP staff have faced threats and abuse during vaccination programme, poll finds. BMJ2021;373:n1665. doi: 10.1136/bmj.n1665 pmid: 34193473

2 Mahase E. Covid-19: GPs urge government to clear up confusion over symptoms. BM/2021;373:n1654. doi: 10.1136/bmi.n1654 pmid: 34183357 him when he would be seen in hospital. The misleading 
3 Mahase E. NHS England's media briefings caused rise in complaints against GPs, say doctors. BM/2020;371:m4684. doi: 10.1136/bmj.m4684 pmid: 33257307 